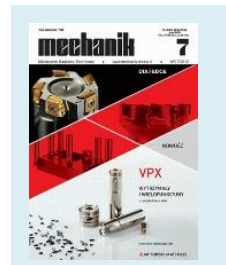

Author: Agnieszka Niedźwiedzka

Title of article: „Numeryczne modelowanie zjawiska kawitacji w dwuwymiarowych zwężkach zbieżno-rozbieżnych z zastosowaniem podejścia homogenicznego" ("Numerical modeling of cavitation phenomenon in a two-dimensional convergingdiverging nozzle using a homogeneous approach")

Mechanik, Vol. 91, No. 7 (2018): pages 520-522

DOI: https://doi.org/10.17814/mechanik.2018.7.71

\title{
Numerical modeling of cavitation phenomenon in a two-dimensional converging-diverging nozzle using a homogeneous approach
}

\author{
Numeryczne modelowanie zjawiska kawitacji \\ w dwuwymiarowych zwężkach zbieżno-rozbieżnych \\ z zastosowaniem podejścia homogenicznego
}

\begin{abstract}
AGNIESZKA NIEDŹWIEDZKA *
\end{abstract}
The article presents results of numerical simulations of cavitation phenomenon in a converging-diverging nozzle using the homogeneous approach. Three cavitation models are considered: the Schnerr and Sauer model, the Singhal et al. model and the Zwart et al. model. The simulations are performed for transient. The geometry is two-dimensional and planar. In the numerical calculations Fluent software was used. The aim of the work is to estimate the possibility of applying of two-dimensional planar numerical simulations of cavitating flows for small-sized converging-diverging nozzles. The motivation to conduct numerical simulations for two-dimensional and planar geometry are difficulties in obtaining results, which reflect experimental measurements, both for two- and three-dimensional geometry. The achieved results show a big similarity between the results of performed numerical simulations and the material from the experimental measurements for all the analyzed models.

KEYWORDS: numerical fluid mechanics, cavitation, homogeneous approach, converging-diverging nozzle

Cavitation is a phenomenon of evaporation of fluid in in the areas, where the static fluid pressure of the fluid drops below the saturated vapour pressure at a given temperature.

To this day, this phenomenon arouses more negative than positive emotions. Cavitation is associated primarily with erosion and noise. Almost no one remembers about its positive aspects, especially as in the literature images of destroyed propulsors and elements of hydraulic systems dominate [2].

\footnotetext{
* Mgr inż. Agnieszka Niedźwiedzka (agnieszka.niedzwiedzka@uwm. edu.pl) - Katedra Mechaniki i Podstaw Konstrukcji Maszyn, Wydział Nauk Technicznych, Uniwersytet Warmińsko-Mazurski w Olsztynie
}

Meanwhile, cavitation is not only the cause of numerous problems with mechanical devices, but in many cases is a factor conditioning the proper functioning of machines.

A very good example of devices that show the positive use of cavitation are diesel injectors. Due to the cavitation bubbles occurring in the throat of the injector orifice, their diameter decreases and the maximum flow velocity increases. In addition, cavitation has a positive effect on the fuel spray angle [1].

\section{Theoretical basics}

The homogeneous approach in the classification of numerical methods of modeling the phenomenon of cavitation is in the area of single-fluid methods. In the one-fluid method, the fluid is treated as a multiphase mixture with an average density for which one set of mass, momentum and energy balance equations is solved. In the homogeneous approach, in addition to the set of equations, one more equation of transport of the selected component should be solved, most often a vapour:

$$
\frac{\partial \rho_{v} \alpha_{v}}{\partial t}+\operatorname{div}\left(\rho_{v} \alpha_{v} \vec{u}\right)=\dot{m}^{+}+\dot{m}^{-}
$$

where: $\rho_{v}$ - vapour density $\left[\mathrm{kg} / \mathrm{m}^{3}\right], \alpha_{\mathrm{v}}$ - vapour volume fraction, $t$ - time [s], $u$ - speed [m/s], $m$ - mass source $\left[\mathrm{kg} /\left(\mathrm{m}^{3} \cdot \mathrm{s}\right)\right]$.

The transport equation is expressed by means of two source elements that describe the evaporation and condensation processes.

Three homogeneous models, available directly from the program interface, were used in the numerical simulations. The mass sources of these models are set in the table. 
TABLE. List of source components of the analyzed homogeneous models of the phenomenon of cavitation

\begin{tabular}{|c|c|c|c|}
\hline \multicolumn{2}{|c|}{ Mass source for the condensation process } & \multicolumn{2}{|l|}{ Mass source for the evaporation process } \\
\hline$\dot{m}^{+}=\frac{\rho_{v} \rho_{l}}{\rho_{m}} \alpha_{v}\left(1-\alpha_{v}\right) \frac{3}{R} \sqrt{\frac{2}{3} \frac{\left(p-p_{\text {sat }}\right)}{\rho_{l}}}$ & (2) & $\dot{m}^{-}=-\frac{\rho_{v} \rho_{l}}{\rho_{m}} \alpha_{v}\left(1-\alpha_{v}\right) \frac{3}{R} \sqrt{\frac{2}{3} \frac{\left(p_{s a t}-p\right)}{\rho_{l}}}$ & (3) \\
\hline$\dot{m}^{+}=C_{p} \frac{\sqrt{k}}{\sigma} \rho_{l} \rho_{l} \sqrt{\frac{2}{3} \frac{\left(p-p_{s a t}\right)}{\rho_{l}}} f_{v}$ & (4) & $\dot{m}^{-}=-C_{d} \frac{\sqrt{k}}{\sigma} \rho_{l} \rho_{v} \sqrt{\frac{2}{3} \frac{\left(p_{s a t}-p\right)}{\rho_{l}}}\left(1-f_{v}-f_{g}\right)$ & $(5)$ \\
\hline$\dot{m}^{+}=C_{p} \frac{3 \alpha_{v} \rho_{v}}{R} \sqrt{\frac{2}{3} \frac{\left(p-p_{\text {sat }}\right)}{\rho_{l}}}$ & $(6)$ & $\dot{m}^{-}=-C_{d} \frac{3 \rho_{v}\left(1-\alpha_{v}\right) \alpha_{n u c}}{R} \sqrt{\frac{2}{3} \frac{\left(p_{s a t}-p\right)}{\rho_{l}}}$ & $(7)$ \\
\hline
\end{tabular}

The first model analyzed in simulations is the Schnerr and Sauer model from 2001 [5]. In the mass sources of this model, there are no empirical constants (equations (2) and (3)). The model is based solely on the quantitative data of physical parameters.

Another model analyzed is the Singhal et al. model from 2002 [6]. The mass sources of this model (equations (4) and (5)) contain both empirical constants for evaporation and condensation processes as well as additional physical parameters in the form of turbulent kinetic energy and surface tension.

The last analyzed model is the Zwart et al. model from 2004 [7]. The source elements of this model (equations (6) and (7)) are characterized by the simplest structure with reference to the previously presented models, however, similar to the model of Singhal et al. they have empirical evaporation and condensation constants.

These models are available directly from the program's interface. In the literature are known more models which could be apply in numerical simulations of cavitating flow [4].

\section{Material and methods}

Numerical simulations of cavitating flow were performed in the Fluent program, which is a part of the Ansys. The flowing medium is water. A time step $t=0.001 \mathrm{~s}$ was applied. The dimensions of the converging-diverging nozzle are shown in fig. 1. The total length of the nozzle is $900 \mathrm{~mm}$ and the length of the inlet part is $170 \mathrm{~mm}$. The outer diameter of the nozzle is $50 \mathrm{~mm}$, the diameter of the throat is $3 \mathrm{~mm}$, and the length of the throat is $6 \mathrm{~mm}$. Convergence and divergence angles are equal to $45^{\circ}$. In the numerical simulations, this geometry is planar. Due to the asymmetric nature of the phenomenon, the use of axisymmetric geometry has been abandoned.

Numerical simulations include data from experimental measurements [4]. An example of the cavitation cloud, made with a high-speed camera, is shown in fig. 2. The linear velocity at the inlet is $0.5 \mathrm{~m} / \mathrm{s}$, and the outlet pressure is equal to atmospheric pressure of $101,328 \mathrm{~Pa}$. The turbulence model used is the $k-\varepsilon$ model.

Three grid densities were analyzed. In the first case the number of cells is 996, on the second level the density increases to 3984 , and on the last - up to 15936 .

\section{Results and discussion}

In numerical simulations of cavitation phenomena, the most important output data are contours of the volume fraction of vapour. Fig. 3 shows the development of cavitation clouds for the mesh with the highest number of cells for considered models. In each of them, the development of the cavitation cloud begins with a small vapour area, appearing just behind the throat, which increases with the passage of time as it moves away from the throat. It is also characteristic that the vapour area is permanently near the bottom edge. Analyzing fig. 3, it can be noticed that the shape of the obtained cavitation cloud just after the cavitation inducer does not go towards the axis of symmetry of the chamber, but towards its lower edge. Only in the further part of the cavitation chamber the cavitation cloud spreads throughout the whole chamber area.

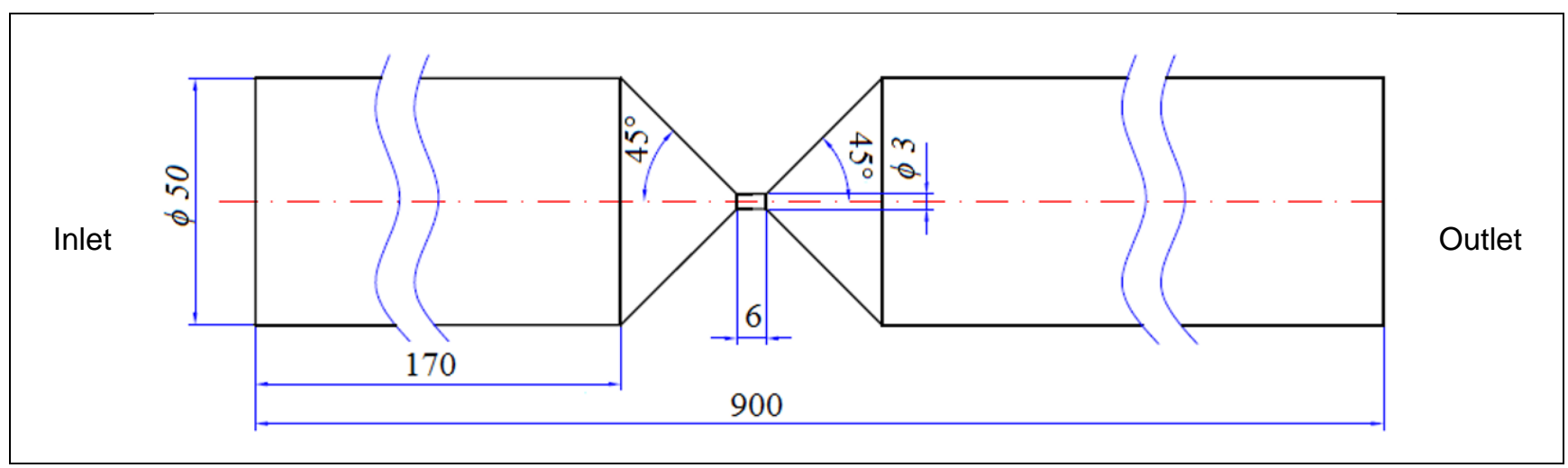

Fig. 1. Dimensions of the analyzed nozzle

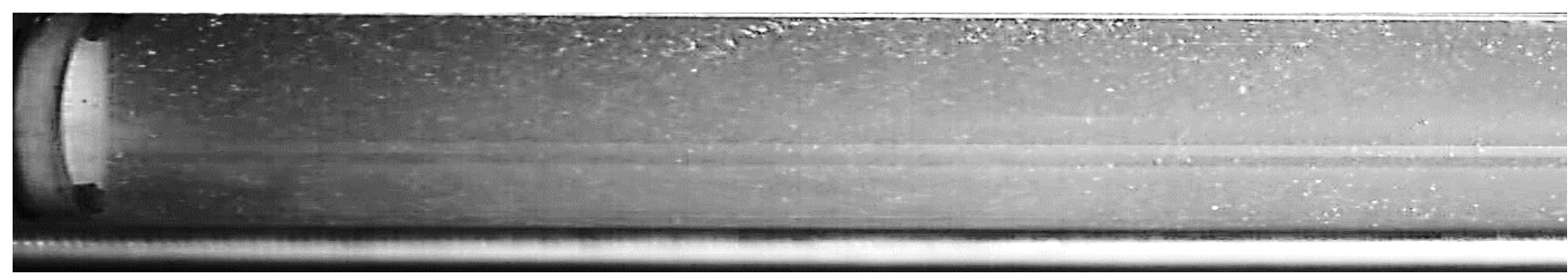

Fig. 2. Example picture of the cavitation cloud (source: Niedźwiedzka and Sobieski, 2016) 


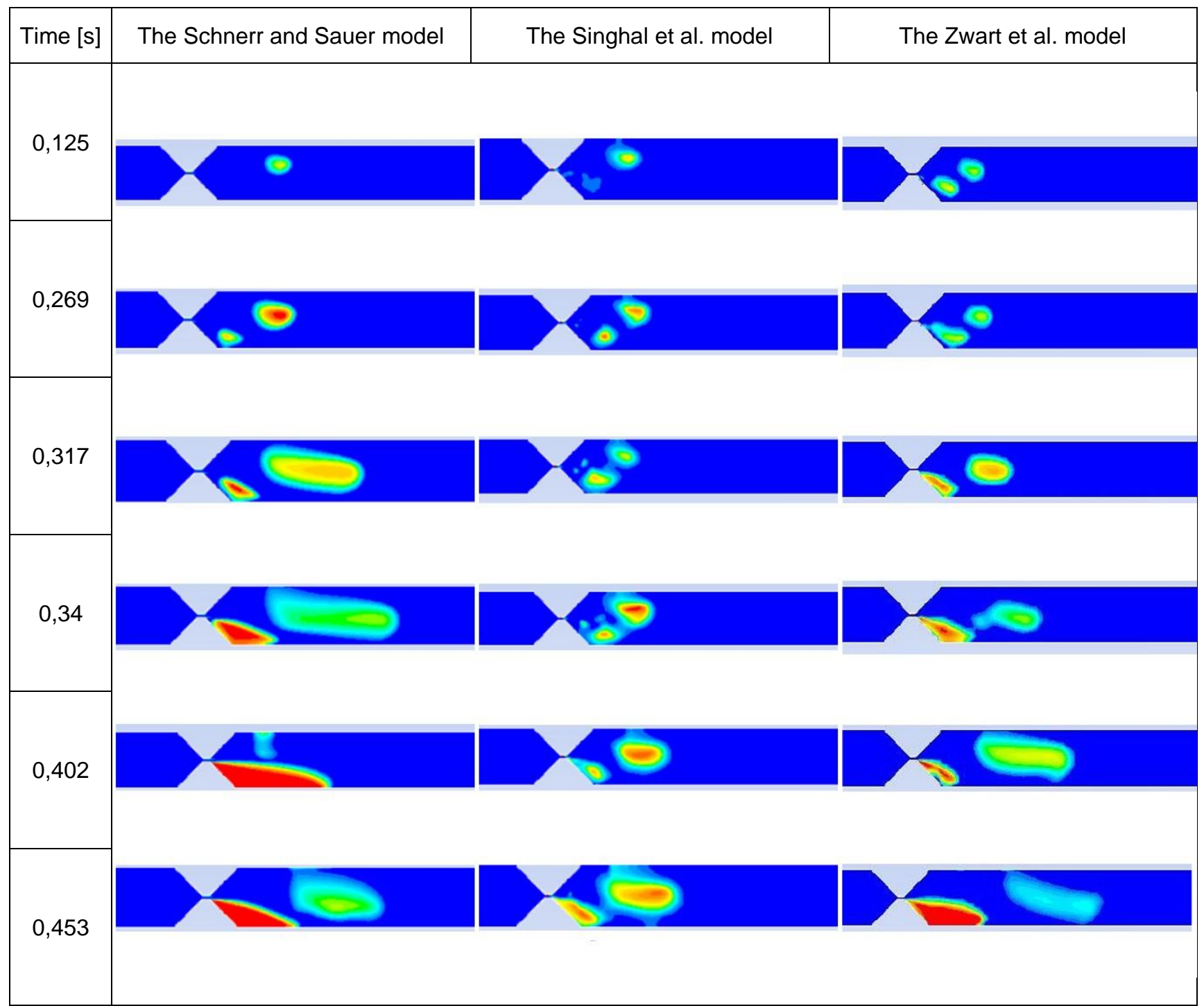

Fig. 3. Contours of the vapour volume fraction in selected time steps for the Schnerr and Sauer, the Singhal et al. and the Zwart et al. models

\section{Conclusions}

The obtained volume fraction of the vapour basically reflects the image of the cavitation clouds from the experimental measurements. It can be concluded that the hook shape observed during experimental measurements has been mapped - just behind the throat, the vapour volume fraction is heading towards the lower edge, and then the cavitation cloud is observed in the central part of the chamber.

The use of planar geometry in the numerical analysis of the phenomenon of cavitation using a homogeneous approach in converging-diverging nozzle may be subjected to further research. The next stage of numerical simulations will be the analysis of the cavitating flow based on the obtained experimental data using three-dimensional geometry.

\section{REFERENCES}

1. Andriotis, A., Gavaises Manolis, Arcoumanis C. "Vortex flow and cavitation in Diesel injector nozzles". Journal of Fluid Mechanics. 610 (2008): pp. 195-215.

2. Gupta Manoj Kumar, Sharma Dharmendra S., Lakhera Vikas J. "Vapor bubble formation, forces, and induced vibration: A review." Applied Mechanics Reviews. 68, 3 (2016): pp. 030801.

3. Niedźwiedzka A., Schnerr G.H., Sobieski W. "Review of numerical models of cavitating flows with the use of the homogeneous approach". Archives of Thermodynamics. 2 (2016): pp. 71-88.
4. Niedźwiedzka A., Sobieski W. "Experimental investigations of cavitating flows in a Venturi tube". Technical Sciences. 19, 2 (2016): pp. 151-164.

5. Schnerr Günther H., Sauer Jürgen. „Physical and numerical modeling of unsteady cavitation dynamics". Proc. of the $4^{\text {th }}$ International Conference on Multiphase Flow (ICMF 2001). New Orleans (USA), 2001

6. Singhal Ashok K., Athavale Mahesh M., Li Huiying, Jiang Yu. "Mathematical basis and validation of the full cavitation model". Journal of Fluids Engineering. 124 (2002): pp. 617-624.

7. Zwart P.J., Gerber A.G., Belamri Thabet. „A two-phase flow model for prediction cavitation dynamics". Proc. of the $5^{\text {th }}$ International Conference on Multiphase Flow (ICMF 2004). Yokohama (Japan), 2004.

Translation of scientific articles, their computer composition and publishing them on the website www.mechanik.media.pl by original articles in Polish is a task financed from the funds of the Ministry of Science and Higher Education designated for dissemination of science.

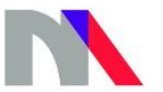

Ministry of Science and Higher Education Republic of Poland 